\title{
Clinical Pattern and Outcome of Acute Heart Failure at the Yaounde Central Hospital
}

\author{
Jérôme Boombhi ${ }^{1,2 *}$, Murielle Moampea1, Liliane Kuate ${ }^{1,2}$, Alain Menanga ${ }^{1,2}$, Bâ Hamadou1,2, \\ Samuel Kingue ${ }^{1,2}$
}

\author{
${ }^{1}$ Faculty of Medicine and Biomedical Sciences, University of Yaoundé I, Yaoundé, Cameroon \\ ${ }^{2}$ Yaoundé General Hospital, Yaoundé, Cameroon \\ Email: *boombhijerome@yahoo.fr
}

How to cite this paper: Boombhi, J., Moampea, M., Kuate, L., Menanga, A., Hamadou, B. and Kingue, S. (2017) Clinical Pattern and Outcome of Acute Heart Failure at the Yaounde Central Hospital. Open Access Library Journal, 4: e3478. https://doi.org/10.4236/oalib.1103478

Received: February 25, 2017

Accepted: March 28, 2017

Published: March 31, 2017

Copyright ( 2017 by authors and Open Access Library Inc.

This work is licensed under the Creative Commons Attribution International License (CC BY 4.0).

http://creativecommons.org/licenses/by/4.0/

\section{Open Access}

\begin{abstract}
Background: Acute heart failure (AHF) is a major public health issue. Our objective was to study its clinical pattern and outcome in a reference hospital in Cameroon. Methods: This was a retrospective observational study, including any patient hospitalized for AHF, diagnosed based on clinical and/or ultrasound evidence, in the Cardiology Department of the Yaounde Central Hospital during a period of 3 years from January $1^{\text {st }} 2013$ to March $30^{\text {th }} 2016$. Data were entered and analyzed using the statistical software Epi info version 7.1.1.14. Results: A total of 148 patients with AHF were included over a total of 445 admissions. It accounted for $33.3 \%$ of admissions. The average age was 61.46 years. The female-male sex ratio was 1.34 . The main cardiovascular risk factors were hypertension (54.79\%). Dyspnea on exertion was the most prevalent symptom (86\%). Hypertensive AHF was the most represented etiopathogenic entity in the series. The main electrocardiographic abnormality found (27.61\%) was atrial fibrillation. Cardiomegaly was found in $44.76 \%$ of the cases. Hyponatraemia and anemia were found in about a quarter of the cases. On echocardiography, $49.61 \%$ of patients had heart failure with a preserved ejection fraction. The main findings were hypertensive heart disease $(30.16 \%)$ and dilated cardiomyopathy (28.57\%). Concerning the management, the most commonly used drugs on admission were loop diuretics; and on discharge, were ACE inhibitors/angiotensin II receptor blockers. Intrahospital mortality was $18.45 \%$. Conclusion: AHF at the Yaounde Central Hospital occurs with severe clinical presentation, complicated by high intra-hospital mortality. Hypertension plays a predominant role both in its onset and in the underlying chronic cardiac involvement.
\end{abstract}

\section{Subject Areas}

Cardiology 


\section{Keywords}

Acute Heart Failure, Clinical Presentation, Outcome, Yaounde Central Hospital

\section{Background}

Heart failure (HF) is a major public health problem worldwide [1]. It is more of a syndrome than a primary diagnosis, with several potential etiologies, various presentations and clinical subtypes.

Acute heart failure (AHF) is characterized by the rapid onset of this syndrome, particularly marked by significant fluid overload with a predominance of signs and symptoms related to congestion [2].

The prevalence of AHF in sub-Saharan Africa continues to increase due to the aging of the population and the presence of hypertension [1]. In Cameroon, there is no national AHF register, but only a few studies on HF are conducted in selected hospitals [3] [4]. The aim of this work is to contribute to a better knowledge of the AHF at the Yaounde Central Hospital.

\section{Material and Methods}

We conducted an observational, descriptive and retrospective study in the Cardiology Department of YCH over a period of 3 years from January $1^{\text {st }} 2013$ to March $30^{\text {th }} 2016$. YCH is a second category reference hospital in Cameroon, and it serves as a university teaching hospital. The number of admission per year is. Patients over the age of 15, hospitalized for AHF were included by consecutive sampling.

Variables collected were socio-demographic, clinical, paraclinical, therapeutic modalities as well as intrahospital evolution.

Data were analyzed using Epi info version 7 software, results expressed as a percentage for the qualitative variables and as mean values with standard deviation for the quantitative variables.

\section{Results}

In the Cardiology Department of the Yaounde Central Hospital, AHF accounted for 30 and $33.3 \%$ of hospitalizations for the years 2014 and 2015 respectively, with a total of 148 patients included in the study. The average age was 61.46 years. A female predominance was noted with 1.34 women for $1 \mathrm{man}$. The main cardiovascular risk factors were hypertension (54.79\%), diabetes (17.12\%) and smoking $(15.75 \%)$. The predominant clinical picture was that of congestive Heart Failure (Table 1).

Dyspnea on exertion was the most prevalent symptom (86\%), with $65.85 \%$ at stage IV of the New York Heart Association (Figure 1).

Hypertensive AHF was the most frequent etiopathogenic entity in our series (Table 2).

Atrial fibrillation was the main electrocardiographic abnormality found 
Table 1. Initial clinical presentation.

\begin{tabular}{ccc}
\hline Clinical picture & Number & Percentage \\
\hline Isolated right heart failure & 11 & $7.91 \%$ \\
Isolated left heart failure & 12 & $8.63 \%$ \\
Congestive heart failure & 116 & $83.45 \%$ \\
Total & 139 & $100 \%$ \\
\hline
\end{tabular}

Table 2. Etiopathogeny categories of AHF.

\begin{tabular}{cc}
\hline Category & Percentage \\
\hline Hypertensive AHF & $42.7 \%$ \\
Decompensated CHF & $37.1 \%$ \\
Isolated right HF & $12.36 \%$ \\
ACS complicated of heart failure & $5.6 \%$ \\
Pulmonary edema & $2.24 \%$ \\
Cardiogenic choc & $00 \%$ \\
TOTAL & $100 \%$ \\
\hline
\end{tabular}

Clinical signs

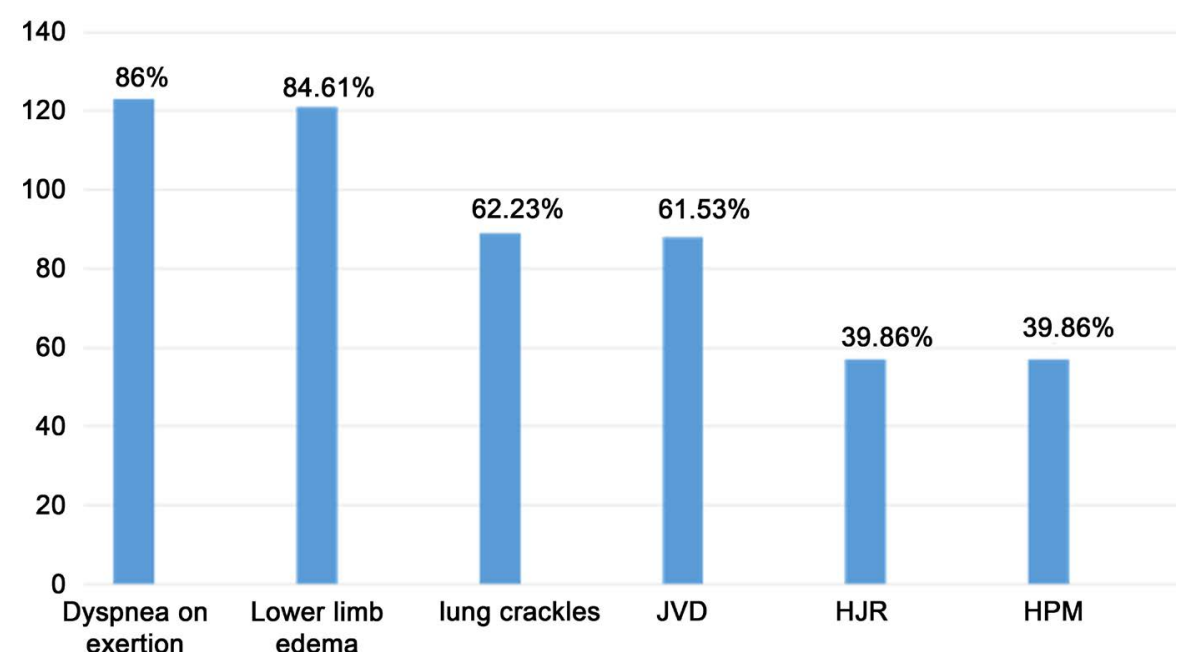

Figure 1. Clinical signs.

(27.61\%). Radiographic cardiomegaly was found in $44.76 \%$ of the cases. Hyponatremia and anemia were found in about a quarter of the cases. A majority of patients had heart failure with a preserved ejection fraction from echocardiography (Table 3).

The main decompensation factor identified in our series was hypertensive crisis. Similarly, hypertensive heart disease was the most common underlying cardiac disease (Table 4).

The main findings were hypertensive heart disease (30.16\%) and dilated cardiomyopathy (28.57\%).

Concerning therapeutics, the most commonly used drugs on admission and 
Table 3. Classification according to left ventricular ejection fraction.

\begin{tabular}{ccc}
\hline LVEF & Number & Percentage \\
\hline More than $\mathbf{5 0 \%}$ & 63 & $49.61 \%$ \\
Less than $\mathbf{4 0 \%}$ & 44 & $34.65 \%$ \\
$\mathbf{4 0 \%}$ to $\mathbf{4 9 \%}$ & 20 & $15.75 \%$ \\
TOTAL & 127 & $100.00 \%$ \\
\hline
\end{tabular}

Table 4. Cardiac diseases in our series.

\begin{tabular}{cc}
\hline Cardiac disease & Percentage \\
\hline Hypertensive heart disease & $30.16 \%$ \\
Dilated cardiomyopathy & $28.57 \%$ \\
Valvular heart disease & $11.90 \%$ \\
Chronic cor pulmonale & $8.73 \%$ \\
Ischemic heart disease & $6.35 \%$ \\
Pericardial diseases & $3.96 \%$ \\
Peri partum cardiomyopathy & $3.18 \%$ \\
\hline
\end{tabular}

discharge were loop diuretics and ACE inhibitors/angiotensin II receptor blockers. Hospital mortality was $18.45 \%$.

\section{Discussion}

Globally, the hospital prevalence of heart failure is less than 10\% [5] [6] [7] [8]. Higher values are found in most African series. These results confirm the predominant role of AHF in hospitals regardless of geographical location.

The mean age of patients with heart failure varies between studies from 64 to 77 years [9] [10]. Our patients had a mean age of 61.46 years [11], with a minimum of 16 years and a maximum of 96 years, which is consistent with the observations of other African studies on AHF [12]. Overall, patients with AHF in Africa are younger than those seen in developed countries [7] [13] [14] [15] [16]. This may be due to the accessibility of health care in developed countries, thus delaying the occurrence of factors favoring the development of this pathology.

Our series had a majority of women $(57.43 \%)$, which is comparable to the findings of Sani MU et al. [17] and in two Haitian series [18] [19]. This could be explained by the predominance of hypertension in women and the presence of PPMC which occurs only in women.

Our findings are consistent with data from literature, presenting hypertension as the main factor associated with HF in sub-Saharan Africa. Diabetes and smoking are also the most common comorbidities associated with hypertension in patients with AHF [12] [13] [15].

Dyspnea on exertion in our patients was predominantly severe (stages 3 - 4), consistent with the findings of Okechukwu S. et al. in a series in Nigeria [20]. This reflected the advanced stage of HF before the consultation. 
The most frequent electrocardiographic abnormality in our series was complete atrial fibrillation, which was permanently present in one quarter of the study population followed by left ventricular hypertrophy in $17.14 \%$ of cases. These two anomalies were also the most common in a similar study conducted at the Sylvanus Olympio Teaching Hospital in Lomé, Togo [15].

Majority (49\%) of our patients had preserved systolic function. This differs from data in the literature, which finds predominant systolic dysfunction in sub-Saharan Africa [4] [12] [14]. The difference in classification of HF according to ejection fraction in different studies could explain this discrepancy [9].

Anemia was also found in 1/4 of patients and was most often multifactorial.

B-type Natriuretic peptides (BNP) were not assayed in our series. Their high cost and diagnosis confirmation using Framingham criteria makes it a diagnostic modality seldom used in our context.

In our series, hypertensive heart disease was the principal cardiac pathology detected by Doppler echocardiography, followed by dilated cardiomyopathy. Its preponderance in our study could be explained by the long evolution of hypertension in our context where screening is not frequently done, so it is often unknown by populations.

In Morocco, the predominant etiology is ischemic heart disease, as in European studies [4] [8] [21] [22] [23]. In our series, ischemic heart disease is poorly represented as it is the case in another African study [24]. The lack of thorough investigation methods, including invasive and non-invasive ischemia tests, may account for its low proportion in our series. As a result, the prevalence of coronary disease is not well defined in our environment and is certainly underestimated.

The use of diuretics, especially loop diuretics, forms the basis of AHF treatment in the hemodynamic stabilization phase. This was the case for $97.87 \%$ of cases in our series. These results are consistent with data found in the literature. The administration of ACE inhibitors/angiotensin II receptor blockers as well as other commonly used therapeutic classes was also consistent with medical practice worldwide [9] [12] [16] [25] [26].

The treatment on discharge in our series was not optimal in the majority of cases, with only $20.55 \%$ of betablockers and approximately $50 \%$ of ACEI/AIIRB, associated with diuretics in $93.24 \%$ of cases, which is similar to findings of Kingue et al. at the Yaounde General Hospital [4]. Ikama et al. in Brazzaville also found a small proportion of beta-blocker prescribed on patient discharge in their series [13].

American and European studies show that treatment recommendations for heart failure are poorly applied [16]. This is particularly true in sub-Saharan Africa, where the implementation of an optimal treatment with titration is particularly difficult because of the lack of patient follow-up.

In our series, AHF has a poor prognosis with $18.45 \%$ of intra-hospital deaths. A similar trend is described in Togo and Haiti with a hospital mortality of $16.4 \%$ and $12 \%$ respectively [15]. This varies between 5.5\% - 14\% in Portuguese series 
and 3.8\% - 12\% in European registers [9]. All these reflect the seriousness of this pathology throughout the world, although its determinants vary according to geographical location.

\section{Conclusion and Recommendations}

Overall, our findings on AHF are similar to those in the literature in sub-Saharan Africa. The improvement of its management involves setting up multidisciplinary teams within organized health networks, as well as optimizing the technical platform.

\section{Acknowledgements}

Acknowledgement to administrative and medical staff of the Yaounde general hospital, the administrative staff of the Faculty of medicine and biomedical sciences.

\section{Declarations}

\section{Ethics approval and consent to participate}

The protocol of this study was approuved by the institutional ethical committee of the Faculty of Medicine and Biomedical Sciences and the national ethical committee. And all participants written consent was obtained.

\section{Consent for publication}

All the authors give thier consent for publication of this manuscript.

\section{Availability of data and material}

Materials and data are availble.

\section{Competing interests}

The authors declare no conflict of interest.

\section{Funding}

No fund was recieved for this study from any organization.

\section{References}

[1] Bloomfield, G.S., Barasa, F.A., Doll, J.A., et al. (2013) Heart Failure in Sub-Saharan Africa. Current Cardiology Reviews, 9, 157-173. https://doi.org/10.2174/1573403X11309020008

[2] Lindenfeld, J., Albert, N.M., Boehmer, J.P., et al. (2010) Executive Summary: HFSA 2010 Comprehensive Heart Failure Practice Guideline. Journal of Cardiac Failure, 16, 475-539. https://doi.org/10.1016/j.cardfail.2010.04.005

[3] Tantchou Tchoumi, J.C., Ambassa, J.C., Kingue, S., et al. (2011) Occurrence, Aetiology and Challenges in the Management of Congestive Heart Failure in Sub-Saharan Africa: Experience of the Cardiac Centre in Shisong, Cameroon. The Pan African Medical Journal, 8, 11.

[4] Kingue, S., Dzudie, A., Menanga, A., et al. (2005) Nouveau regard sur l'insuffisance cardiaque chronique de l'adulte en Afrique à l'ère de l'échocardiographie Doppler: expérience du service de médecine de l'Hôpital Général de Yaoundé. Annales de Cardiologie et d'Angéiologie, 54, 276-283.

https://doi.org/10.1016/j.ancard.2005.04.014 
[5] Antony, K.K. (1980) Pattern of Cardiac Failure in Northern Savanna Nigeria. Tropical and Geographical Medicine, 32, 118-125.

[6] Oyoo, G.O. and Ogola, E.N. (1999) Clinical and Socio Demographic Aspects of Congestive Heart Failure Patients at Kenyatta National Hospital, Nairobi. East African Medical Journal, 76, 23-27.

[7] Amoah, A.G. and Kallen, C. (2000) Aetiology of Heart Failure as Seen from a National Cardiac Referral Centre in Africa. Cardiology, 93, 11-18. https://doi.org/10.1159/000006996

[8] Douay, I., Benchakroune, D., Bendagha, N., et al. (2013) Prise en charge de l'insuffisance cardiaque dans un CHU au Maroc. Maroc Médical, 35.

[9] Senni, M., Tribouilloy, C.M., Rodeheffer, R.J., et al. (1998) Congestive Heart Failure in the Community: A Study of All Incident Cases in Olmsted County, Minnesota, in 1991. Circulation, 98, 2282-2289. https://doi.org/10.1161/01.CIR.98.21.2282

[10] Damasceno, A., Bongani, M.M., Sani, M., et al. (2012) The Causes, Treatment, and Outcome of Acute Heart Failure in 1006 Africans from 9 Countries: Results of the Sub-Saharan Africa Survey of Heart Failure. Archives of Internal Medicine, 172, 1386-1394. https://doi.org/10.1001/archinternmed.2012.3310

[11] Steinhart, B., Thorpe, K.E., Bayoumi, A.M., et al. (2009) Improving the Diagnosis of Acute Heart Failure Using a Validated Prediction Model. Journal of the American College of Cardiology, 54, 1515-1521. https://doi.org/10.1016/j.jacc.2009.05.065

[12] Ikama, M.S., Nsitou, B., Mongo-Ngamanis, S., et al. (2013) Causes de réadmission pour insuffisance cardiaque au CHU de Brazzaville. Cardiovascular Journal of Africa, 24, 11.

[13] Ojji, D.B., et al. (2009) Pattern of Heart Failure in Abuja, Nigeria: An Echocardiographic Study. Cardiovascular Journal of Africa, 20, 349-352.

[14] Kheyi, J., Benelmakki, A., Bouzelmat, H., et al. (2016) Epidémiologie et prise en charge de l'insuffisance cardiaque dans un centre marocain. The Pan African Medical Journal, 24, 85. https://doi.org/10.11604/pamj.2016.24.85.8521

[15] Fonsecaa, C., Araújoa, I., Marquesa, F., et al. (2016) A Closer Look at Acute Heart Failure: Putting Portuguese and European Data into Perspective. Revista Portuguesa de Cardiologia, 35, 291-304. https://doi.org/10.1016/j.repc.2015.10.011

[16] Sani, M.U., Davison, B.A., Cotter, G., et al. (2014) Renal Dysfunction in African Patients with Acute Heart Failure. European Journal of Heart Failure, 16, 718-728. https://doi.org/10.1002/ejhf.103

[17] Malebranche, R., Tabou Moyo, C., Morisset, P.H., et al. (2016) Clinical and Echocardiographic Characteristics and Outcomes in Congestive Heart Failure at the Hospital of the State University of Haiti. American Heart Journal, 178, 151-160. https://doi.org/10.1016/j.ahj.2016.06.001

[18] Kwan, G.F., Bukhman, A.K., Miller, A.C., et al. (2013) A Simplified Echocardiographic Strategy for Heart Failure Diagnosis and Management within an Integrated Noncommunicable Disease Clinic at District Hospital Level for Sub-Saharan Africa. JACC: Heart Failure, 1, 230-236. https://doi.org/10.1016/j.jchf.2013.03.006

[19] Ojji, D., Stewart, S., Ajayi, S., et al. (2013) A Predominance of Hypertensive Heart Failure in the Abuja Heart Study Cohort of Urban Nigerians: A Prospective Clinical Registry of 1515 de Novo Cases. European Journal of Heart Failure, 15, 835-842. https://doi.org/10.1093/eurjhf/hft061

[20] Ogah, O.S., Sliwa, K., Akinyemi, J.O., et al. (2015) Hypertensive Heart Failure in Nigerian Africans: Insights from the Abeokuta Heart Failure Registry. The Journal of Clinical Hypertension (Greenwich), 17, 263-272. 
https://doi.org/10.1111/jch.12496

[21] Thiam, M. (2001) Insuffisance cardiaque en milieu cardiologique africain. 6ème congrès international francophone de médecine tropicale "Santé et urbanisation en Afrique", Dakar, Octobre 2001, manuscrit nºK/77.

[22] Nieminen, M.S., Brutsaert, D., Dickstein, K., et al. (2006) EuroHeart Failure Survey II (EHFS II): A Survey on Hospitalized Acute Heart Failure Patients: Description of Population. European Heart Journal, 27, 2725-2736.

https://doi.org/10.1093/eurheartj/ehl193

[23] Commerford, P. and Mayosi, B. (2006) An Appropriate Research Agenda for Heart Failure in Africa. The Lancet, 367, 1884-1886.

https://doi.org/10.1016/S0140-6736(06)68822-3

[24] Kwan, G.F., Waking, J.B., Philip, C., et al. (2016) Descriptive Epidemiology and Short-Term Outcomes of Heart Failure Hospitalisation in Rural Haiti. Heart (British Cardiac Society), 102, 140-146. https://doi.org/10.1136/heartjnl-2015-308451

[25] Pio, M., Afassinou, Y., Pessinaba, S., et al. (2014) Epidémiologie et étiologies des insuffisances cardiaques à Lomé. Pan African Medical Journal, 18, 183.

[26] Ntusi, N.B. and Mayosi, B.M. (2009) Epidemiology of Heart Failure in Sub-Saharan Africa. Expert Review of Cardiovascular Therapy, 7, 169-180.

https://doi.org/10.1586/14779072.7.2.169

\section{List of Abbreviations}

AHF: Acute heart failure

HF: Heart failure

NYHA: New York Heart Association

PPMC: Peripartum myocardiopathy

Submit or recommend next manuscript to OALib Journal and we will provide best service for you:

- Publication frequency: Monthly

- 9 subject areas of science, technology and medicine

- Fair and rigorous peer-review system

- Fast publication process

- Article promotion in various social networking sites (LinkedIn, Facebook, Twitter, etc.)

- Maximum dissemination of your research work

Submit Your Paper Online: Click Here to Submit

Or Contact service@oalib.com 